\title{
The Impact of Human Capital Development on Economic Growth in Ethiopia
}

\author{
Shemsedin Abdu Dawud \\ Department of Economics, Mekdela Amba University, Mekane Selam, Ethiopia \\ Email address: \\ shemsedinabdu5@gmail.com \\ To cite this article: \\ Shemsedin Abdu Dawud. The Impact of Human Capital Development on Economic Growth in Ethiopia. American Journal of Theoretical \\ and Applied Business. Vol. 6, No. 4, 2020, pp. 47-51. doi: 10.11648/j.ajtab.20200604.11
}

Received: October 5, 2020; Accepted: October 22, 2020; Published: November 19, 2020

\begin{abstract}
The importance of human capital accumulation as an engine of economic growth and development has been widely recognized in theoretical and empirical studies. No country has achieved sustained economic development without substantial investment in human capital. In accordance with this, Ethiopia has made some movements to create skilled and competent citizens through designing different education and health policies and implementing them. This study investigates the impact of human capital on economic growth in Ethiopia over the period 1980-2018. The model was estimated using the Co-integrated VAR approach. The result of this study showed that in the long run both ratios of government expenditure on health and education to GDP, Labor force and policy change dummies have positive impact on Ethiopian economy. In other words, the result reveals that economic performance can be improved significantly when the variables increase. However, Gross primary school enrollment shows a negative relationship with economic growth during the study period. The estimated short-run model revealed that gross primary school enrollment is the main contributor to real GDP. But, unlike its long run significant impact, Ratio of government expenditure on education has no significant short run impact on the economy. In addition, ratios of government expenditure on health and labor force have negative significant impact on the economy.
\end{abstract}

Keywords: Human Capital, Economic Growth, Health, Education, Gross Primary School Enrolment, Labor Force, Vector Error Correction Model

\section{Background of the Study}

Societies in general aspire for development. It is believed that economic growth explain much of the development aspect, nations spend significant part of their resources and time in an effort to guarantee sustained economic growth [1].

Human capital refers to the acquired and useful abilities of all the inhabitants or members of the society and Human capital has been recognized globally as one major factor that is responsible for the wealth of nations [2]. The meaning of once nation wealth has augmented to accommodate not only physical capital but also human capital as an independent factor of production required to accomplish high and sustainable economic growth rates.

Modern theory of economic growth argues that human capital, especially education and health has the principal role on achieving economic growth and development [3]. In accordance with this, Ethiopia has made some movements to create skilled and competent citizens through designing different education and health policies and implementing them [4].

The intimate linkage amongst health and education has been firmly settled in a number of studies which could potentially reinforce each other towards a rapid socioeconomic development of a country, especially in developing economies like Ethiopia.

Education in Ethiopia has been dominated by the Ethiopian Orthodox Church for a long time. The more planned and coordinated system of education was recorded during the imperial period of Haile Selassie. The primary target of education had been to deliver trained manpower that could run the emergent state administration. Hence the imperial regime trust that education held the key to Ethiopia's development they establish the ministry of Education in 1942. From 1942 to 1955 the Ethiopian government engaged in the expansion of education system by giving high government budget this activity leads to rapid 
growth of student enrolment within the nation [5].

After 1974 revolution, During the Derg administration, the structure and organization of educational activities were changed alongside the objectives of the socialist government which states, "There will be an educational program that will give free education, step by step, to the broad masses". The military regime worked toward a more even distribution of schools by concentrating its efforts on small towns and rural areas that had been neglected during the Imperial regime. With the specialized help from the Ministry of Education, individual communities performed all primary school construction. The regime also nationalized all private schools, with the exception of church-affiliated ones, and made them part of the public school system. One of the success stories in the socialist regime has been the achievement in terms of reduction of illiteracy rate in the country. Despite the fact that, the Derg has grater accomplishment on expanding distribution of education it failed to build on what was already achieved in previously. That is, Private sector development and the development of the market incentive structure both in the education sector and in the labor market were highly discouraged [6].

After the downfall of the military regime, in 1994 education Sector Strategy was designed by the current government. The main objective of the strategy was: changing curriculum; expanding primary, secondary and tertiary level education; improving the quality of education; making education more relevant to the demands of the community; restructuring the organization and administration of the education system [6].

The major health problems of the country remain to a great extent preventable communicable diseases and nutritional disorders. In spite of significant advance made to enhance the wellbeing status of the population in the last two decades, Ethiopians still face a high rate of morbidity and mortality and the health status remains relatively poor [7].

After changes of Government in 1991, the government created the health policy which was the first of its kind in the country and was among the various political and socialeconomic transformation measures that were put in place. The center elements of health policy are democratization and decentralization of the health care system, development of the preventive, promotive and curative components of health care, assurance of accessibility of health care for all segments of the population and the promotion of private sector and NGOs participation in the health sector [8].

\section{Methodology}

\subsection{Data Type and Source}

This study conducts the empirical analysis by employing data sets for the period 1980-2018 for all the variables specified in the model. The necessary data used for the study are secondary time series data. Data of Real Gross Domestic Product, Ratio of Government Expenditure on education to GDP, Ratio of Government Expenditure on Health to GDP and Labor force are obtained from National Bank of Ethiopia. On the other hand, data's of Gross primary school enrollment is extracted from World Development Indicators from World Bank [9].

\subsection{Theoretical Framework and Model Specification}

In line with theoretical framework developed by [10], this study specify the model that shows the relationship between economic growth and human capital in Ethiopia as follows; Real gross domestic product (RGDP) is specified as a function of ratio of government expenditure on education to GDP, Ratio of government expenditure on health to GDP, Labor force, Gross primary school enrollment and policy change. Moreover, the variables are preferred based on their relevance and data availabilities.

$$
\text { RGDP }=\mathrm{f}(\text { RGEE, RGEH, LF, GPSE, D1) }
$$

Finally, the above equations specified as;

$$
\mathrm{LNRGDP}=\beta 1+\beta 2 R G E E+\beta 3 \mathrm{RGEH}+\beta 4 L F+\beta 5 \mathrm{GPSE}+\beta 6 \mathrm{D} 1+\text { et }
$$

Where: LNRGDP is the logarithm of Real Gross domestic product, RGEE is the ratio of government expenditure on education to GDP, RGEH is the ratio of Government expenditure on health, LF is the Labor force, GPSE is Gross primary school enrollment and D1 is the policy change dummy variable.

\section{Empirical Results and Discussion}

The aim of this study is to analyze the relationship between human capital development and economic growth using annual data from 1980-2018 in Ethiopia using recent econometric technique of cointegrated VAR approach. The discussion begins by describing the data set and Before we go to the direct estimation of the model, we need to first employ the unit root test to check whether the time-series is stationary or not. After identifying the optimal lag length, the presence of the co-integrating vectors is tested using the Johansen procedure. Further the long-run and short-run relationship is also identified.

\subsection{Descriptive Analysis}

Summary Statistics and Distributional Results

In this section summary statistics (mean and standard deviation) and distributive summary (skewness and kurtosis) of all variables are discussed. The result of summary statistics and summary distribution are presented in tabular form below. 
Table 1. Descriptive Statistics of Variables

\begin{tabular}{|c|c|c|c|c|c|c|c|}
\hline Variables & Obs & Mean & Standard Deviation & Minimum & Maximum & skewness & Kurtosis \\
\hline LNRGDP & 38 & 12.348 & 0.5020574 & 11.5308 & 13.52214 & 0.75079 & 2.27338 \\
\hline RGEE & 38 & 3.7594 & 1.471702 & 2.09821 & 5.66677 & 0.44545 & 1.64533 \\
\hline RGEH & 38 & 1.9676 & 0.78008 & 0.42219 & 3.835156 & 0.39595 & 1.89206 \\
\hline GPSE & 38 & 57.231 & 25.77977 & 21.483 & 98.787 & 0.46654 & 1.65607 \\
\hline
\end{tabular}

Source: own computation.

The above table depicted the description of variables used in the estimation. The LNRGDP averages 12.348 and varies from 11.5308 to 13.52214 with a standard deviation of 0.5020574. RGEE averages 3.7594 and goes from 2.09821 to 5.66677. Similarly, RGEH averages 1.9676 and ranges from 0.42219 to 3.835156. And Labor force, with a mean of 24.272 , also varies from a minimum of 12.63 to a maximum of 41.78. Finally, GPSE averages 57.231 goes from 21.483 to 98.787 with a standard deviation 25.77977 .

Based on the measure of symmetry as indicated by the result of skewness, the data set on any of the variable is said to be symmetrical if and only if the value of skewness is approximately zero. The data is negatively skewed when its value of skewness is less than zero and it is positively skewed when the value of the skewness is greater than zero. From the above table it is clear that all variables are skewed to the right or simply they are positively skewed.

The other measure in the summery statics is kurtosis, which measures whether the given data is normally distributed or not. The variable is said to be normally distributed when the quantitative value for kurtosis is less than three. In this study the value of kurtosis is less than three for all variables included in the model indicating that all variables are normally distributed.

\subsection{Econometric Result and Analysis}

\subsubsection{Unit Root Test}

While working with time series data, testing for stationarity is an essential. The outcomes we get by using non-stationary time series may be spurious. That is, they may indicate a relationship between variables which does not exist. In order to obtain a consistent and reliable result, we must transform the non stationary data into stationary data by differencing. In contrast to the non-stationary process that has a variable variance and a mean that does not remain near, or returns to a long-run mean over time, the stationary process reverts around a constant long-term mean and has a constant variance independent of time [11].

This test can be done using the Augmented Dickey-Fuller (ADF) unit root tests. The ADF test is an extension of the Dickey-Fuller test because the regression has been augmented with the lagged changes. When the ADF test statistics is larger than the critical value in absolute terms, the null hypothesis of unit root is rejected, and if the ADF test statistics is less than the critical value in absolute terms, we fail to reject the null hypothesis.

Table 2. Unit root test result

\begin{tabular}{|c|c|c|c|c|c|c|}
\hline \multirow{2}{*}{ Variables } & \multirow{2}{*}{$\begin{array}{l}\text { Test-statistics } \\
\text { at level }\end{array}$} & \multirow{2}{*}{$\begin{array}{l}\text { Test statistics at } \\
\text { difference }\end{array}$} & \multicolumn{3}{|c|}{ Critical Values } & \multirow{2}{*}{$\begin{array}{l}\text { Decision for } \\
\text { Stationarity }\end{array}$} \\
\hline & & & $1 \%$ & $5 \%$ & $10 \%$ & \\
\hline LRGDP & 2.195 & -4.264 & -3.682 & -2.972 & -2.618 & At difference \\
\hline RGEH & -0.937 & -5.261 & -3.682 & -2.972 & -2.618 & At difference \\
\hline LF & 2.210 & -4.655 & -3.682 & -2.972 & -2.618 & At difference \\
\hline GPSE & 0.604 & -3.252 & -3.682 & -2.972 & -2.618 & At difference \\
\hline
\end{tabular}

Source: own computation.

The absolute values of the calculated test statistics for all variables are less than its critical value at given level of significance. The result indicates that all variables are nonstationary at level, i.e, the series appears to have unit root. So the null hypothesis that each variable has unit root cannot be rejected by the Augmented Dickey Fuller test. However, after applying the first difference, we reject the null hypothesis since the data appears to be stationary at first difference. Therefore all variables are integrated of order one I (1).

\subsubsection{Cointegration Test}

VAR Lag Length Selection Criteria
The ADF test confirmed that all the variables of the study are integrated of order one so cointegration tests are possible. The Johansen co-integration test result is very sensitive to the number of lags included for the endogenous variables in the estimation of the VAR. This necessitates the determination of an optimal lag order prior to the test of co-integration. The optimal lag order is determined with the Akaike Information Criterion (AIC), the sequential modified Likelihood Ratio test statistics (LR), the Final Prediction Error (FPE), the Schwarz Information Criterion (SIC), and the Hannan-Quinn Information Criterion (HQ). 
Table 3. VAR Lag Order Selection Criteria

\begin{tabular}{lllllll}
\hline Lag & Log L & LR & FPE & AIC & SC & HQ \\
\hline 0 & -210.835 & & .020535 & 13.1415 & 13.4136 & 13.2331 \\
1 & -17.1352 & 387.4 & $1.5 \mathrm{e}-06$ & $3.58395^{*}$ & $5.4886^{*}$ & 4.2248 \\
2 & 22.0397 & 78.35 & $1.6 \mathrm{e}-06$ & 3.39153 & 6.92873 & 4.58169 \\
3 & 82.5065 & $120.93^{*}$ & $7.1 \mathrm{e}-07^{*}$ & 1.9087 & 7.07845 & $3.64816^{*}$ \\
\hline
\end{tabular}

* indicates lag order selected by the criterion.

Source: own computation.

The above table indicates that, the Akaike Information Criterion (AIC) and Schwarz Information Criterion (SIC) and chose one lag length to be the optimum lag length. The smaller is the value of the information criteria, the better the model. Hence this study employs the optimal lag length of one for estimation techniques.

Johansen Cointegration Test
Since the variables are integrated of order one, we proceed to test for co-integration [13]. Cointegration test is applied at the predetermined lag 1. In these tests, Maximum Eigen value statistic or Trace statistic is compared to special critical values. The maximum Eigen value and trace tests proceed sequentially from the first hypothesis no cointegration to an increasing number of cointegrating vectors.

Table 4. Johansen Cointegration Test Results.

\begin{tabular}{lllll}
\hline \multirow{2}{*}{ Maximum Rank } & \multirow{2}{*}{ Eigen value } & \multicolumn{2}{l}{ Trace statistic } & \multicolumn{2}{l}{ Maximum eigen value Statistic } \\
\cline { 3 - 5 } & & t-statistic & Critical Value & t-statistic \\
\hline 0 & 0.64906 & 102.7891 & 94.15 & 39.37 \\
1 & 0.59213 & $66.1394^{*}$ & 68.52 & 31.3884 \\
2 & 0.36015 & 34.7510 & 47.21 & 15.6282 \\
3 & 0.25675 & 19.1227 & 29.68 & 10.3853 \\
4 & 8.7374 & 15.41 & 73.64 \\
\hline
\end{tabular}

*Denotes rejection of the hypothesis at the 0.05 level.

Source: Own computation.

The above table demonstrates the results of Cointegration test. The trace statistic indicates that at least one cointegrating vector $(r \geq 1)$ exists in the system at the 95 percent confidence level (estimated LR statistic, 102.7891 > $94.15,95$ per cent critical value). In order to cross check for identifying the specific number of cointegrating vectors, the maximal Eigen value statistic is further employed. This statistic confirms the existence of only one cointegrating relationship at the 95 per cent confidence level in this system (estimated LR statistic, $39.37>36.6498$, 95 per cent critical value).

\subsubsection{Vector Error Correction Model}

After having determined the existence of long run relationship between variables the Vector error correction model is determined. The Vector error correction has cointegration relations built into the detail so that it restricts the long-run behavior of the endogenous variables to merge their cointegrating relationships while permitting for shortrun adjustment dynamics [12].

Table 5. Estimated Long Run Model, Dependent variable: LNRGDP.

\begin{tabular}{llll}
\hline Variable & Coefficient & Std. Err. & $\mathbf{P}>|\mathbf{z}|$ \\
\hline LNRGDP & 1 &. &. \\
RGEE & 1.669011 & 0.2664684 & 0.003 \\
RGEH & 0.8250655 & 0.2776399 & 0.000 \\
GPSE & -0.1324626 & 0.0167911 & 0.000 \\
LF & 0.102538 & 0.0496605 & 0.039 \\
D 1 & 3.436097 & 0.4757282 & 0.000 \\
Constant & -13.71172 &. &. \\
\hline
\end{tabular}

Source: own computation.

We can rewrite the long run equilibrium equation as follows:

$$
\mathrm{LNRGDP}=\beta 1+\beta 2 R G E E+\beta 3 \mathrm{RGEH}+\beta 4 L F+\beta 5 \mathrm{GPSE}+\beta 6 \mathrm{D} 1
$$

$$
\mathrm{LNRGDP}=-13.71172+1.669011 \mathrm{RGEE}+0.8250655 \mathrm{RGEH}-0.1324626 \mathrm{GPSE}+0.102538 \mathrm{LF}+3.436097 \mathrm{D} 1
$$

As it is shown in Table 5 all the variables on the model are statistically significant in the long run. The estimated coefficients of Ratio of government expenditure on education, Ratio of government expenditure on health, Labor force and the policy change dummy have positive signs. While the sign for the coefficient of Gross primary enrollment is negative labor force.

Short Run Relationships

The short run model is estimated and the result summarized in table below
Table 6. Short Run Coefficients.

\begin{tabular}{llll}
\hline Variables & Coefficients & Standard Error & $\mathbf{P}>|\mathbf{z}|$ \\
\hline ECM & -0.0245573 & 0.0213626 & 0.0268 \\
D_rgee & -0.1657053 & 0.1225808 & 0.176 \\
D_rgeh & -0.2722026 & 0.0908121 & 0.003 \\
D_lf & -0.5103266 & 0.1697808 & 0.003 \\
D_gpse & 0.2097282 & 0.1265944 & 0.0468 \\
D_d1 & 0.1109341 & 0.0593455 & 0.042 \\
\hline
\end{tabular}

Source: own computation. 
The above table shows the results of the D (RGDP) equation in the error-correction model, from which the shortrun impact of Ratio of Government expenditure on education to GDP, Ratio of Government expenditure on health to GDP, labor force, Gross primary school enrollment, and policy change variable can be analyzed.

The coefficient of cointegrated equation shows that the error correction term for the equation is negative and statistically significant. This tells us that there is a reasonable adjustment towards the long run steady state [14]. This guarantees that although the actual real per capita GDP may temporarily deviate from its long-run equilibrium value, it would gradually converge to its equilibrium. Based on the result in the above table, $2.4 \%$ of the disequilibrium in one period will be corrected in the subsequent period.

As can be seen from above table the short run estimates revealed that Gross primary school enrollment is the main contributor to economy in the short run. But, unlike its long run significant impact, RGEE has no significant short run impact on the economy. Ratios of government expenditure on health to GDP and labor force have negative significant coefficient indicating that it has distortional impact in short run during the study period.

When the error-correction model was estimated, a dummy variable was included in order to capture the effect of liberalization of trade and the macroeconomic regime [15]. The positive and significant coefficient of dummy for liberalization suggests that the policy liberalization positively affected real per capita GDP growth.

\section{Conclusion and Policy Implication}

The result of this study showed that in the long run both ratios of government expenditure on health and education to GDP, Labor force and policy change dummies have positive impact on Ethiopian economy. In other words, the result reveals that economic performance can be improved significantly when the variables increase. However, Gross primary school enrollment shows a negative relationship with economic growth during the study period.

In the short run, the coefficient of error correction term is 0.0245573 suggesting about 2.45 percent annual adjustment towards long run equilibrium. This is another proof for the existence of a stable long run relationship among the variables.

The estimated short-run model reveals that gross primary school enrollment is the main contributor to real GDP. But, unlike its long run significant impact, Ratio of government expenditure on education has no significant short run impact on the economy. In addition, the ratios of government expenditure on health to GDP and labor force have negative significant impact on the economy.

The finding depicts that government expenditure on education and health are positively related to economic growth and it brings a significant effect in the long run.

Based on this, investing in more and better-distributed education and health would help to create conditions that could lead to higher productivity and hence higher economic growth.

\section{References}

[1] Tewodros, G. (2015), "The determinants of Economic Growth in Ethiopia: A Time series analysis", unpublished Master Thesis, Addis Ababa University, Addis Ababa, Ethiopia.

[2] Folloni, G. and Vittadini, G. (2010). Human capital Measurement: A Survey, Journal of Economic Surveys, 24 (2), 248-279.

[3] Gyimah-Brempong, K. and M. Wilson (2005). Human Capital and Economic Growth. Is Africa Different? Journal of African Development, 7 (1): 73-109.

[4] Kidanemariam, G. (2013), "The Impact of Human Capital Development on Economic Growth In Ethiopia: Evidence from ARDL Approach to Co-Integration", A Peer-Reviewed Indexed International Journal of Humanities \& Social Science, II (IV), April-2014.

[5] MoE. (2008). National Report of the Federal Democratic Republic of Ethiopia: Development of Education and Inclusive Education. Ministry of Education, Addis Ababa, Ethiopia.

[6] Woubet, K. (2006). Human Capital and Economic Growth in Ethiopia, unpublished Master Thesis, Addis Ababa University, Addis Ababa, Ethiopia.

[7] MoH. (2010). Health Sector Development Programme IV: Final draft. Ministry of Education, Addis Ababa, Ethiopia.

[8] HSDP, (2010), "Health Sector Development Program", Addis Ababa, Ethiopia.

[9] World Bank, (2019), "World Bank, World Bank Data base", last updated: 23 March, 2019, Washington DC.

[10] Mankiw, G., Romer, D. and N. Weil (1992). A Contribution to the Empirics of Economic Growth. Quarterly Journal of Economics, 107 (2): 407-437.

[11] Banerjee, A., Dolado, J., Galbraith, J., and D. Hendry (2003). Co-integration, Error Correction, And the Econometric Analysis of Non-stationary Data: Advanced Text in Econometrics New York: Oxford university press.

[12] Engle, F. and Granger, J. (1987). Co-Integration and Error correction: Representation, Estimation and Testing, Journals of Econometrica, 55 (2): 251-276.

[13] Johansen, S. (1995). Estimation and Hypothesis Testing of Cointegration Vectors in Gaussian Vector Autoregressive Models. Econometrica, 59, 1551-1580.

[14] Harris, R. (1999). Using Co-integration Analysis in Econometric Modeling. London, Prentice hall.

[15] Chandran G.; Ramesh R. and Sajid R. (2010), "Economic growth and Government spending in Malaysia; a reexamination of wagner and Keynesian Views", springer seines and Business media Vol. 44 pp. 203-219. 